\title{
Clinical, Laboratory, and Ultrasound Characteristics of Knee Involvement in Children With Juvenile Rheumatoid Arthritis
}

\author{
Hisham M. Habib ${ }^{a}$, Ghada O. Elsedfy, ${ }^{\mathrm{b}, \text {, Dalia A Shaheen }}{ }^{\mathrm{c}}$, Ashraf A. Essa ${ }^{\mathrm{d}}$
}

\begin{abstract}
Background: The aim of this study was to evaluate clinical, laboratory, and ultrasound characteristics of the knee involvement a cohort of juvenile rheumatoid arthritis patients.

Methods: Nineteen JRA children with mean age of 10.2 years were recruited. Clinical assessment of the knee score was performed. Patients with a mean total score $\geq 1$ were classified as having active knee involvement. The following measurements were recorded: Ritchie articular index score, Steinbrocker grading system, and the Childhood Health Assessment Questionnaire. Visual analog scale. Laboratory investigations were performed, including complete blood count, erythrocyte sedimentation rate, C-reactive protein, and rheumatoid factor, antinuclear antibodies. Knee ultrsonography was done for both knees of all patients on the same day as the clinical and laboratory investigation.
\end{abstract}

Results: Active knee group comprised 12 patients with 17 active knees. Mean Ritchie articular index score, was found to be $15.2 \pm$ 9.6, mean of Steinbrocker grading system was $2 \pm 1.2$, while mean of Childhood Health Assessment Questionnaire was 1.2 \pm 1.1 , and that of Visual analog scale was $3.8 \pm 2.4$. Laboratory characteristics of patients with knee involvement showed a statistically A significant increase in ESR [ $54.5 \pm 18.9$ vs. $24.3 \pm 14.8, \mathrm{p}=0.001] \mathrm{CRP}$ levels [22.7 \pm 11.4 vs. $12.6 \pm 4 \mathrm{p}=0.011]$, and decrease in hemoglobin concentration $[9.4 \pm 2.7$ vs. $12.6 \pm 2.4, \mathrm{p}=0.02]$. Ultrasonography characteristics showed a statistically significant increase in knee synovial thickness and knee effusion volume.

Conclusions: knee joint is considered a mirror image for the activ-

Manuscript accepted for publication October 3, 2012

${ }^{a}$ Department of Rheumatology and Rehabilitation, Mansoura University, Egypt

${ }^{b}$ Department of Pediatrics, Assiut University, Egypt

${ }^{c}$ Department of Medical Biochemistry, Mansoura University, Egypt

${ }^{\mathrm{d}}$ Department of Radiodiagnosis, Bani Sweef University, Egypt

${ }^{\mathrm{e}}$ Corresponding author:Ghada O. Elsedfy, Department of Pediatrics,

Assiut University, Assiut, 71515 Egypt. Email: gelsedfy@hotmail.com

doi: http://dx.doi.org/10.4021/ijcp45w ity status of patients with JRA, with a clinical, laboratory and ultrasonic activity data consistent with the pathological profile inside the knee.

Keywords: Juvenile rheumatoid arthritis; Knee joint; Clinical; Laboratory; Ultrsonography

\section{Introduction}

Juvenile rheumatoid arthritis (JRA) is the most common chronic rheumatic illness in children and is a significant cause of both short- and long-term disabilities [1]. It is comprised of a heterogeneous group of several disease subtypes that are characterized by the onset of arthritis before the age of 16 years and has symptoms lasting at least 6 weeks [2].

Any joint can be affected by JRA, but large joint are more frequently involved than smaller joints [3]. The knee is the most commonly affected joint in JRA, and overall accounts for the most disability [4].

The diagnosis of JIA is essentially a clinical one. Therefore, laboratory investigations are used to confirm the diagnosis and to aid in disease classification [5]. Furthermore, the ability of plain radiographs to detect radiological changes in early arthritis is limited. Based on that, there is a real need for other radiological variables to assess the joints in patients with arthritis [6].

In juvenile idiopathic arthritis (JIA), proliferative changes in the synovium and synovial fluid accumulation are pathological findings responsible for damage to the cartilaginous tissue and periarticular bone, which are late radiographic findings in conventional radiography. Early detection of these joint changes would allow the clinicians to initiate relevant therapies as is essential for the long-term outcome of JIA. Ultrasonography (US) has shown great potential for this purpose but validation in a pediatric setting is needed [7].

The aim of this study was to evaluate clinical, laboratory, and ultrasound characteristics of the knee involvement a cohort of juvenile rheumatoid arthritis patients. We considered the validation of US measurements of local joint activity in collaboration with clinical and laboratory findings. 

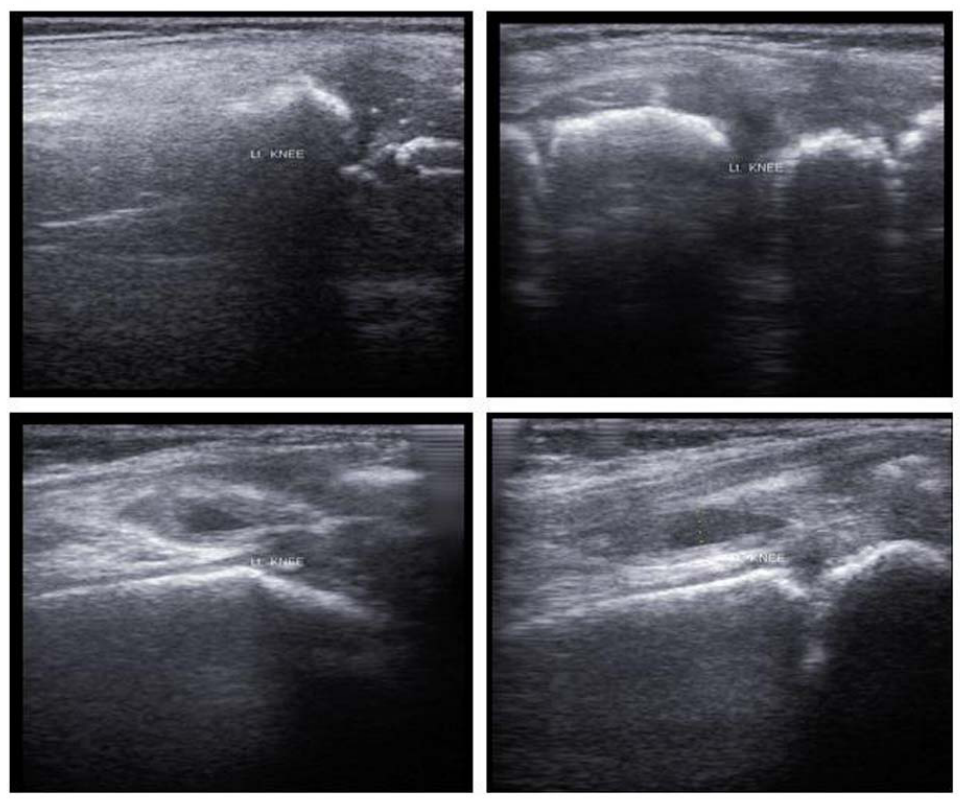

Longitudinal scan of the supra patellar pouch reveal an increase in knee synovial thickenning and knee effusion in a patient with juvenile rheumatoid arthritis

Figure 1. Ultrsonographic image of active knee in one patient with JRA.

\section{Patients and Methods}

A total of 19 children (12 female and 7 male) with mean age of 10.2 years (range of 2 - 14.5 years) who met American College of Rheumatology criteria for JIA diagnosis [8] were enrolled for this study.

The study was approved by the hospital ethical committee and a written informed consent was taken from all patients' and controls' guardians who agreed to contribute in the study with full information about the study and procedures may request to do.

All patients were subjected to full history taking (either patient or parent if inconvenient), clinical examination with stress of the locomotors system. Clinical assessment of the knee including presence of pain (score 1 or absence score 0 ), degree of swelling (score 0 absence, score 1 mild, score 2 moderate, score 3 severe), degree of limitation of extension (no limitation score $0,<5^{\circ}$ limitation of extension score $1,<10^{\circ}$ limitation of extension score $2,<15^{\circ}$ limitation of extension score $3,>15^{\circ}$ limitation of extension score 4 ). Patients with a mean total score $\geq 1$ were classified as having active knee involvement, while patients with normal physical findings were considered to be in clinical remission [10]. According to the above-mentioned clinical assessment score of the knee, patients were divided into 2 groups; group with active knee joint and group with inactive knee joint. Active knee group included those whose score $\geq$ 1 , and inactive knee group included those whose score $<1$. The following measurements were recorded: Ritchie articu- lar index score for assessing joint tenderness [9]. Functional capacity of the patients was assessed using the Steinbrocker grading system [11] and the Childhood Health Assessment Questionnaire (CHAQ) [12]. Clinical knee assessment of disease activity was performed using Visual analog scale $(0-10 \mathrm{~cm})$.

\section{Laboratory investigations}

Laboratory investigations were performed for all patients, including complete blood count, erythrocyte sedimentation rate by Wintergreens method, and $\mathrm{C}$ - reactive protein detection by the latex agglutination slide test, and rheumatoid factor (RF), antinuclear antibodies (ANA).

Five milliliters of venous blood was collected from each subject and divided into three samples. The first one was used for complete blood count, the second one for erythrocyte sedimentation rate by Westergren method. The third blood sample was used for quantitative determination of antinuclear antibodies (IgG, IgA, and IgM), quantitative determination of RF and C-Reactive protein.

Human serum levels of ANA were measured using ELISA (IMTEC-ANA screen ITC 60001) (HUMAN-GERMANY). The readings were measured on an ELISA reader (HumaReader HS) at $450 \mathrm{~nm}$ [13].

CRP and Serum human levels of RF were measured turbidimetrically at $552 \mathrm{~nm}$, and at $583 \mathrm{~nm}$ respectively using COBAS INTEGTRA 400 machine; Roche Diagnostics, Indianapolis, Ind) $[14,15]$. 
Table 1. Clinical Characteristics of all JRA Patients

\begin{tabular}{ll}
\hline Variable & Data \\
\hline Disease duration (months) mean \pm SD (range) & $53.3 \pm 17.5(4-103)$ \\
JRA subtype & \\
- polyarticular & $8 / 19(42.1 \%)$ \\
- oligoarticular & $8 / 19(42.1 \%)$ \\
- systemic & $3 / 19(15.8 \%)$ \\
Active knee joint patients' $n(\%)$ & $12 / 19(63.1 \%)$ \\
Bilateral clinical knee involvement $n(\%)$ & $5(26.3 \%)$ \\
Ritchie articular index score, mean \pm SD & $15.2 \pm 9.6$ \\
Steinbrocker grading system, mean \pm SD (grade $0-4)$ & $2 \pm 1.2$ \\
Childhood Health Assessment Questionnaire (CHAQ), mean \pm SD & $1.2 \pm 1.1$ \\
Visual analog scale (0 - 10 cm), mean \pm SD & $3.8 \pm 2.4$ \\
\hline
\end{tabular}

\section{Ultrasonic assessment of knee}

USG was done for both knees of all patients on the same day as the clinical and laboratory investigation using the Midose SA 9900 with a $7.5 \mathrm{mHz}$ linear probe and color Doppler. Sagittal images of the suprapatellar bursa were obtained with the patient in the recumbent position and the knee in $30 \%$ flexion. A standardized procedure was followed. The ultrasound transducer was positioned longitudinally above the patella, and the synovial thickness was measured when the probe touched the middle portion of the patellar base, then we measure the total synovial thickness (with electronic calipers and corresponding to the largest anteroposterior diameter of the suprapatellar pouch). This was done by applying firm compression with the transducer to express the suprapatellar fluid into the joint recesses. Assessment of intra-articular fluid was performed by measuring the length of the suprapatellar bursa. Longitudinal images were obtained with manual compression of the lateral synovial recesses to express all intra-articular fluid into the suprapatellar bursa. Transverse diameters were also obtained for the longitudinal images, followed by depth measurements in the transverse images. The volume of fluid was calculated accordingly.

\section{Statistical analysis}

All statistical calculations were performed using computer programs Microsoft Excel version 7 (Microsoft Corporation, NY, USA) and SPSS version 15 (Statistical Package for the Social Science; SPSS Inc., Chicago, IL, USA) statistical pro- gram. Data were statistically described in terms of mean and standard deviation ( $\pm \mathrm{SD}$ ). Comparison of the studied groups was done using the student's $t$ test. Chi square test was uses to compare categorical variables. A p-value less than 0.05 were considered statistically significant.

\section{Results}

\section{Clinical characteristics of all JRA patients (Table 1)}

In this study we recruited 19 patients who were already diagnosed as JRA. Patients were 12 females and 7 males, with controls 12 females and 7 males. In patients, mean age was 9.5 years with range $3.5-15.5$ years.

Clinical characteristics of all patients include the following data. Disease duration was $53.3 \pm 17.5$ months with a range of $4-103$ months. For JRA patients subtypes, 8 (42.1\%) were polyarticular subtype, 8 (42.1\%) were oligoarticular subtype and $3(15.8 \%)$ were systemic onset subtype. As mentioned before, and according to clinical assessment score of the knee, patients were divided into 2 groups; group with active knee joint and group with inactive knee joint. Active knee group included those whose score $\geq 1$, and inactive knee group included those whose score $<1$. Active knee group comprised 12 patients with 17 active knees. Five patients had active bilateral knees and 7 had unilateral active knee. Bilateral clinical knee involvement was found in 5 patients (26.3\%). Mean Ritchie articular index score, was found to be 15.2 \pm 9.6 , mean of Steinbrocker grading system was $2 \pm 1.2$, while mean of Childhood Health Assessment 
Table 2. Clinical, Laboratory, and Ultrasonography Characteristics of Knee Involvement of JRA Patients

\begin{tabular}{|c|c|c|c|c|}
\hline & Variable & $\begin{array}{l}\text { Patients with } \\
\text { active knee }\end{array}$ & $\begin{array}{l}\text { Patients with } \\
\text { inactive knee }\end{array}$ & P value \\
\hline \multirow[t]{4}{*}{ Clinical } & (1) Ritchie articular index score, mean \pm SD & $19.5 \pm 5.8$ & $10.1 \pm 4.5$ & 0.0014 \\
\hline & (2) Steinbrocker grading system, mean $\pm \mathrm{SD}$ & $3.2 \pm 1.2$ & $1.1 \pm 0.7$ & 0.0002 \\
\hline & $\begin{array}{l}\text { (3) Childhood Health Assessment Questionnaire (CHAQ), } \\
\text { mean } \pm \text { SD }\end{array}$ & $2.2 \pm 1.2$ & $1.1 \pm 0.4$ & 0.0155 \\
\hline & (4) Visual analog scale $(0-10 \mathrm{~cm})$, mean $\pm \mathrm{SD}$ & $6.8 \pm 3.2$ & $2.7 \pm 1.4$ & 0.002 \\
\hline \multirow[t]{8}{*}{ Laboratory } & (1) Complete blood count (CBC) & & & \\
\hline & - Hemoglobin $(\mathrm{g} / \mathrm{dL})$, mean \pm SD & $9.4 \pm 2.7$ & $12.6 \pm 2.4$ & 0.0208 \\
\hline & - Leucocytosis (n positive) $(\%)$ & $5 / 12(41.7 \%)$ & $1 / 7(14.3 \%)$ & 0.2155 \\
\hline & - Thrombocytosis (n positive) $(\%)$ & $6 / 12(50 \%)$ & $2 / 7(28.6 \%)$ & 0.3614 \\
\hline & (2) ESR (mm/hour), mean \pm SD & $54.5 \pm 18.9$ & $24.3 \pm 14.8$ & 0.0015 \\
\hline & (3) CRP level $(\mathrm{mg} / \mathrm{L})$, mean $\pm \mathrm{SD}$ & $22.7 \pm 11.4$ & $12.6 \pm 4$ & 0.0117 \\
\hline & (4) Rheumatoid factor ( $\mathrm{n}$ positive) $(\%)$ & $5 / 12(41.7 \%)$ & $2 / 7(28.6 \%)$ & 0.5681 \\
\hline & (5) ANA (n positive) $(\%)$ & $2 / 12(16.7 \%)$ & $2 / 7(28.6 \%)$ & 0.5392 \\
\hline \multirow{2}{*}{$\begin{array}{l}\text { Ultra- } \\
\text { sonographic }\end{array}$} & (1) USG knee synovial thickness $(\mathrm{mm})$, mean $\pm \mathrm{SD}$ & $3.2 \pm 1.8$ & $1.1 \pm 0.9$ & 0.0047 \\
\hline & (2) USG knee effusion volume $(\mathrm{mL})$, mean $\pm \mathrm{SD}$ & $4.3 \pm 2.4$ & $2.1 \pm 0.9$ & 0.0141 \\
\hline
\end{tabular}

$\mathrm{n}=$ number, $\mathrm{ESR}=$ erythrocyte sedimentation rate, $\mathrm{CRP}=\mathrm{C}$-reactive protein, $\mathrm{ANA}=$ antinuclear antibody, USG = ultrsonography.

Questionnaire (CHAQ) was 1.2 \pm 1.1 , and that of Visual ana$\log$ scale was $3.8 \pm 2.4$.

\section{Clinical, laboratory, and ultrsonography characteristics of knee involvement of JRA patients (Table 2)}

Clinical characteristics of patients with knee involvement showed a statistically significant increase in Ritchie articular index score $[19.5 \pm 5.8$ vs. $10.1 \pm 4.5, \mathrm{p}=0.001]$, the Steinbrocker grading system $[3.2 \pm 1.2$ vs. $1.1 \pm 0.7, p$ $=0.0002]$, and the Childhood Health Assessment Questionnaire (CHAQ) score [2.2 \pm 1.2 vs. $1.1 \pm 0.4, \mathrm{p}=0.01]$ and visual analog scale (VAS) $(\mathrm{cm})[6.8 \pm 3.2$ vs. $2.7 \pm 1.4, \mathrm{p}=$ 0.002 ] in patients with active knee involvement if compared with patients with inactive knee involvement.

Laboratory characteristics of patients with knee involvement showed a statistically insignificant increase in leucocytic count $[41.7 \% \mathrm{vs} 14.3 \% \mathrm{p}=0.2]$ and thrombocytic counts $[50 \%$ vs. $28.6 \%, \mathrm{p}=0.36]$, rheumatoid factor $[41.7 \%$ vs. $28.6 \%, p=0.5]$ and ANA [16.7\% vs. $28.6, p=0.5]$. A significant increase in ESR (mm/hour) [54.5 \pm 18.9 vs. 24.3 $\pm 14.8, \mathrm{p}=0.001] \mathrm{CRP}$ levels $(\mathrm{mg} / \mathrm{L})[22.7 \pm 11.4$ vs. 12.6 $\pm 4, \mathrm{p}=0.011]$, and decrease in hemoglobin concentration $(\mathrm{g} / \mathrm{dL})[9.4 \pm 2.7$ vs. $12.6 \pm 2.4, \mathrm{p}=0.02]$ in patients with active knee involvement if compared with patients with inactive knee.

Ultrasonography characteristics of patients with knee involvement showed a statistically significant increase in knee synovial thickness $(\mathrm{mm})[3.2 \pm 1.8$ vs. $1.1 \pm 0.9, \mathrm{p}=0.004]$, and knee effusion volume $(\mathrm{mL})[4.3 \pm 2.4$ vs., $2.1 \pm 0.9, \mathrm{p}=$ $0.01]$ in patients with active knee involvement if compared with patients with inactive knee.

\section{Discussion}

This study was performed to evaluate clinical, laboratory, and ultrasound characteristics of the knee involvement in a cohort of juvenile rheumatoid arthritis patients. Our study used clinical assessment score of the knee as a method to define active and inactive knee involvement in JRA patients. Many clinical variables were utilized in the study to compare patients with active knee with those with inactive knee involvement; including Ritchie articular index, Steinbrocker grading system, Childhood Health Assessment Questionnaire (CHAQ) and visual analog scale (VAS). Keeping in mind that JRA is a disease of sparse laboratory findings [5], we tried to link knee disease activity patients with some 
laboratory indices like hemoglobin concentration, presence of leucocytosis, throbocytosis, ESR and CRP levels, RF and ANA positivity. Moreover, we relied upon ultasonographic data in detection of anatomical changes happened in involved active and inactive knee in our cohort.

Our results revealed that there was a statistically significant increase in many of the clinical disease activity and functional limitations measures like Ritchie articular index, Steinbrocker grading system, Childhood Health Assessment Questionnaire (CHAQ) and visual analog scale (VAS) in patients with active knee involvement if compared with patients with inactive knee involvement. The same findings was noticed in many laboratory indices like anemia, high ESR, and CRP level and ultrasonographic activity variables like increased synovial membrane thickness and joint effusion in patients with active knee involvement if compared with patients with inactive knee involvement. Of notice, was the consistency of the clinical and laboratory variables with findings of ultrasonography of the involved knees like increased synovial membrane sickness and synovial effusion.

It is established that the knee is the joint most frequently affected in patients with JRA $[4,16]$. In spite of that, reports addressing knee joint involvement in JRA active versus inactive patients from clinical, laboratory and ultrsonography characteristics were not so frequent. Our results were comparable to other reports. Algergawy et al -in their studyreported that there was a statistically significant difference between clinically active and inactive knees with regard to knee synovial thickness and knee effusion volume detected by knee ultrasonography. They reported positive correlations were found between knee synovial thickness and articular index (AI) scores, disease activity score, clinical knee scores, erythrocyte sedimentation rate (ESR), and C-reactive protein (CRP) levels, visual analog scores, disease activity scores, clinical knee scores, ESR, and CRP levels [17]. Moreover, data obtained from study of Frosch et al confirmed the high sensitivity of arthrosonography in imaging changes in hip and knee joints of patients with JRA. They stressed that sonographic effusion of the knee provided the highest correlation with measures of clinical disease activity [18]. A review of Graham TB emphasized that imaging provides useful information to supplement clinical and laboratory examination in the optimal treatment of patients with juvenile arthritis. He stressed on the usefulness of magnetic resonance imaging and ultrasound can demonstrate both inflammatory and destructive changes, with the utilization of these techniques to show inflammatory changes can provide information about joints that can supplement physical examination [19].

Our results that emphasize a harmony of clinical, laboratory as well as the ultrasongraphic manifestation of disease activity of the knee in affected JIA patients are going in the same manner of the pathogenesis of joint inflammation in JRA. TNF- $\alpha$ and IL-1 produced by activated monocytes, macrophages, and synovial fibroblasts likely have primary roles in the pathogenesis of JRA. These cytokines are detected in synovial fluids or tissues in a majority of JRA patients $[20,21]$.

Finally, it is wise to report that we had not classified our patients according to their clinical subtype, and we did our workup thoroughly in our cohort. It may be useful if we investigate the behavior of patients with active knee joint and the character of knee involvement in different JRA subtype. We recommend further studies investigating that issue.

In conclusion, knee joint is considered a mirror image for the activity status of patients with JRA, with consistent clinical, laboratory and ultrasonographic findings of active joint. This reflects what pathologically happened into the joint.

\section{Disclosure}

None

\section{References}

1. Hahn YS, Kim JG. Pathogenesis and clinical manifestations of juvenile rheumatoid arthritis. Korean J Pediatr. 2010;53(11):921-930.

2. Kim KH, Kim DS. Juvenile idiopathic arthritis: Diagnosis and differential diagnosis. Korean J Pediatr. 2010;53(11):931-935.

3. Hahn YS, Kim JG. A clinical study on pauciarticular juvenile rheumatoid arthritis. J Korean Pediatr Soc 1995;38:386-396.

4. El-Miedany YM, Housny IH, Mansour HM, Mourad HG, Mehanna AM, Megeed MA. Ultrasound versus MRI in the evaluation of juvenile idiopathic arthritis of the knee. Joint Bone Spine. 2001;68(3):222-230.

5. Boros C, Whitehead B. Juvenile idiopathic arthritis. Aust Fam Physician. 2010;39(9):630-636.

6. Pinals RS, Masi AT, Larsen RA. Preliminary criteria for clinical remission in rheumatoid arthritis. Arthritis Rheum. 1981;24(10):1308-1315.

7. Spannow AH, Stenboeg E, Pfeiffer-Jensen M, Fiirgaard B, Haislund M, Ostergaard M, Andersen NT, et al. U1trasound and MRI measurements of joint cartilage in healthy children: a validation study. Ultraschall Med. 2011;32 Suppl 1:S110-116.

8. Brewer EJ, Jr., Bass J, Baum J, Cassidy JT, Fink C, Jacobs J, Hanson V, et al. Current proposed revision of JRA Criteria. JRA Criteria Subcommittee of the Diagnostic and Therapeutic Criteria Committee of the American Rheumatism Section of The Arthritis Foundation. Arthritis Rheum. 1977;20(2 Suppl):195-199.

9. Ritchie DM, Boyle JA, McInnes JM, Jasani MK, Dalakos TG, Grieveson P, Buchanan WW. Clinical studies 
with an articular index for the assessment of joint tenderness in patients with rheumatoid arthritis. Q J Med. 1968;37(147):393-406.

10. Sureda D, Quiroga S, Arnal C, Boronat M, Andreu J, Casas L. Juvenile rheumatoid arthritis of the knee: evaluation with US. Radiology. 1994;190(2):403-406.

11. Steinbrocker O, Trager GH, Butterman RC. Theraputic criteria in juvenile rheumatoid arthritis. JAMA. 1949; 140:659-662.

12. Singh G, Athreya BH, Fries JF, Goldsmith DP. Measurement of health status in children with juvenile rheumatoid arthritis. Arthritis Rheum. 1994;37(12):1761-1769.

13. Muro Y. Antinuclear antibodies. Autoimmunity. 2005;38(1):3-9.

14. Sager D.Wernick RM, Davey MP. Assays for Rheumatoid factor: a review of their utility and limitations in clinical practice .Lab Med .1992; 23:15-18.

15. Eda S, Kaufmann J, Roos W, Pohl S. Development of a new microparticle-enhanced turbidimetric assay for C-reactive protein with superior features in analytical sensitivity and dynamic range. J Clin Lab Anal. 1998;12(3):137-144.

16. Karim Z, Wakefield RJ, Quinn M, Conaghan PG, Brown AK, Veale DJ, O'Connor P, et al. Validation and repro- ducibility of ultrasonography in the detection of synovitis in the knee: a comparison with arthroscopy and clinical examination. Arthritis Rheum. 2004;50(2):387-394.

17. Algergawy S, Haliem T, Al-Shaer O. Clinical, laboratory, and ultrasound assessment of the knee in juvenile rheumatoid arthritis. Clin Med Insights Arthritis Musculoskelet Disord. 2011;4:21-27.

18. Frosch M, Foell D, Ganser G, Roth J. Arthrosonography of hip and knee joints in the follow up of juvenile rheumatoid arthritis. Ann Rheum Dis. 2003;62(3):242-244.

19. Graham TB. Imaging in juvenile arthritis. Curr Opin Rheumatol. 2005;17(5):574-578.

20. Grom AA, Murray KJ, Luyrink L, Emery H, Passo MH, Glass DN, Bowlin T, et al. Patterns of expression of tumor necrosis factor alpha, tumor necrosis factor beta, and their receptors in synovia of patients with juvenile rheumatoid arthritis and juvenile spondylarthropathy. Arthritis Rheum. 1996;39(10):1703-1710.

21. Kutukculer N, Caglayan S, Aydogdu F. Study of pro-inflammatory (TNF-alpha, IL-1alpha, IL-6) and T-cell-derived (IL-2, IL-4) cytokines in plasma and synovial fluid of patients with juvenile chronic arthritis: correlations with clinical and laboratory parameters. Clin Rheumatol. $1998 ; 17(4): 288-292$. 